\title{
Study on the Application of Zen Aesthetics in Plant Landscape Design
}

\author{
Yang Yin \\ Department of Art Design, Chongqing Aerospace Polytechnic, Chongqing, China
}

Keywords: Zen; Aesthetics; Plant landscape design.

\begin{abstract}
Zen is one of the major branches of Mahayana Buddhism in China. Zen aesthetics is an aesthetic ideology which evolved from Zen thoughts. Plant landscape design has a long history in China. In different periods of history, Zen aesthetics has had a deep or shallow impact on plant landscape design. The application of Zen aesthetics in plant landscape design is not only an old subject, but also a new one. This paper expounds and analyses the concept of Zen aesthetics, the aesthetic principle of plant landscape design and the plant landscape design under the guidance of Zen aesthetics.
\end{abstract}

Plant landscape design has a long history in China. According to the literature, the earliest records about plant landscape design can be date back to Shang and Zhou Dynasties of China. The original "park" is the prototype of plant landscape design.

Zen is one of the branches of Buddhism, and it is also the branch of Chinese Mahayana Buddhism. Zen Buddhism advocates self realization and decides to participate in meditation. Zen seeks for a thorough interpretation of things. After Buddhism was introduced to the East, Zen thought has a great influence on the formation of Zen in China. Although Zen spread from ancient India, it merged with Confucianism and Taoism of the central mainland after Sui and Tang Dynasties and developed into a Zen culture with Chinese cultural connotations. Zen has unique views on things and emphasizes the dialectical relationship in preordained fate.From the beginning, Zen came into being influenced Chinese artistic creation and cultural connotations. From a certain point of view, Zen aesthetics is the application of traditional Chinese humanistic spirit of Zen culture in arts.

In the Tang and Song dynasties of the feudal society, the influence of Zen was the most complicated and profound. Aesthetics in the late Tang and Song Dynasties can generally be divided into four categories, namely, Zen aesthetics, Chusao aesthetics, Taoist aesthetics and Confucian aesthetics. Academic circles generally believe that Confucian aesthetics is the beginning of Chinese traditional aesthetics, while Zen aesthetics is the mature stage of Chinese ancient aesthetics. The influence of Zen aesthetics on Chinese art forms is very extensive. It is easy to see the image of Zen aesthetics in ancient Chinese art forms, such as calligraphy, painting, sculpture, poetry, architecture and so on. The aesthetic idea of Zen aesthetics is very large and has played a very important role in expanding traditional Chinese aesthetics.

Zen aesthetics promote the concept of beauty to a new height. The essence of Zen is to achieve the state of getting out of the plain world and examining things from a completely different perspective instead of just focusing on the appearance of things. Zen aesthetics is the most profound understanding and elaboration of aesthetics.

The combination of the plant landscape design and Zen aesthetics has had profound influence to the design of the loyal gardens and the towns of China historically.

\section{The intrinsic value relationship between plant landscape design and Zen aesthetics}

With the development of economy and society, Chinese people have paid more attention to quantity than quality. With the continuous improvement of people's living conditions, people's requirements for plant landscape design have also changed. Many people liked fashion and modern in the past, but now they are beginning to pursue practicality and comfort, which is similar to the purpose of Zen. Harmony between man and nature and of all things are very important parts of Zen 
concepts. Nowadays more and more people would like to combine Zen aesthetics into design to achieve the harmony between man and nature. According to the essence of Zen, practitioners must reach the state of seeing the essence of one thing in the constant learning and understanding, that is, seeing the essence not just the appearance of one thing. Zen requires practitioners to look at everything with meditation and enlightenment, and finally achieve the purpose of epiphany and reach the returning to nature. Zen aesthetics must first emphasize the harmonious unity of man and nature. From a certain perspective, pursuing nature and advocating the truth are the essence of Zen.

For a long time, in the eyes of most people, plant landscape design only meets the needs of garden space composition and artistic composition. The ultimate goal of plant landscape design is to serve social life. People's requirements for plant landscape design are also in the process of continuous development and evolution with the change of living standards. In recent years, in some developed countries, independent individuals such as architecture are no longer simply regarded as encouraging life components, but as a link in the overall chain of human life. Many scholars have proposed the concept of human - architecture - environment based on this. The core of this concept is to ecologize human life and put forward very high requirements for human settlement environment and plant landscape design. In short, the ecological design concept is to try to hide the design feeling in the plant landscape design, so that the design completely merges in the natural situation.

It can be seen that in the future plant landscape design, the harmony relationship between human and the nature and the unity of things and self-transcendence will dominate, which has broad and close value associations with Zen.

\section{The concept of plant landscape design under the guidance of Zen aesthetics}

\subsection{Take simplicity as the main style}

Being nature comes first in Zen aesthetics, and plant landscape design based on Zen aesthetics focuses on simplicity, that is, the plant landscape design should be as simple as possible, the original characteristics of the plant and the environment should be maximized and the design ideas should be shown in a clean and neat style.

\subsection{Advocate nature}

The modern plant landscape design based on Zen should try to reduce the factors of human factors, discard to impose modifications for visual effects, but focus on humanistic color and spirits. First of all, designers should not blindly add redundant design content, but should return to nature and take pure nature as main goal of design.

\subsection{Pay attention on static beauty}

Zen pays great attention to static beauty and strives to show the quiet of Zen pursuit in a static design. Therefore, the plant landscape design based on Zen should reduce the layers, try best lay out the static beauty which is independent of the world.

The beauty of plant landscape design based on Zen should be a subtle beauty, and the mountains and stones have much fun. Freehand technique is used to spread the beauty of plant landscape design and penetrate into all aspects of plant landscape design. The overall layout of the primary design should be close to nature, but cannot mechanically imitate nature. We should place our feelings on the scenery in the most desalinated way, express our feelings through the scenery, and create empty inspiration as far as possible in the limited design space. "The winding path leads to the secluded place, the Zen room is deep and the flowers are deep. Everything is silent, but the sound of the clock is heard.” This poem was made by Wang Wei, a poet of the Tang Dynasty in China. It describes the scene of the Buddhist temple. The author expresses his own feeling of the landscape. In the design of traditional gardens in China, great attention was paid to set off the virtual spirit of Zen through the space environment. The thought of Zen also deeply influence the ancient garden builders. They tried their best to use the natural way of Taoism to make use of 
artificial craftsmanship, but always remembered to erase the traces left by the artificial, and finally made people believe that although the garden is designed by artificial craftsmanship, it looks natural. In Zen concepts, techniques are used to compensate for the traces of human intervention to express natural and agile natural beauty, and to do everything possible to avoid dullness and rigidity which will be caused by artificial craftsmanship.

The line between limited and infinite are broken in Zen thoughts, and Zen believes that the heart is where the world comes from. The idea of Zen makes the structure of small and large, close and far does no longer exist, providing an infinite spiritual experience for the limited creative space. Under the influence of Zen thoughts, creators often create a grand and powerful attitude by small and near things.

Zen also pays attention to the twists and turns of the plant landscape design. The design should be corresponding, not complex. Just as "the winding path leads to the secluded place" in the previous poem, a large space is formed from the connection of many small spaces, which is a circle of loopholes and a state of wit and humor. Zen also pays great attention to the sense of falsehood, which emphasizes the pursuit of the imaginary space through the things that are not spoken. The artistic conception of the static and the virtual shows the intangible and infinite charm. Viewers will have a deep thinking of Zen through the comparison between static and dynamic.

\section{Elements in plant landscape design under the guidance of Zen aesthetics}

Many elements are needed in plant landscape design, the first of which is plants. Green is commonly used in Chinese traditional garden design and the garden is often full of green. The plants which flourish and wither once every year are often used by Zen to express Zen thoughts. Most of the plants are light and simple. The overall layout is clear but not complicated. The varieties of plants are not single or numerous. In the ancient Chinese Zen garden design, bamboo and plum are often used. At the same time, mountains and rivers are also the materials in Zen to express people's mood. In plant landscape design, the appropriate landscape of maintains and rivers gives a natural and free spirit. Architecture is also one of the elements that Zen often uses. The imaginary structure of the building of Zen shows the poetic and artistic structure. A pavilion can be built at a small place and a building group can be arranged in the large place. The common point of architectural design and construction is to fully consider the natural factors and rely on the natural environment.

Of course, Zen aesthetics is based on Chinese native culture. In recent years, the countries, such as Japan, South Korea and other countries which were deeply influenced by Zen culture have also carried out many studies on Zen and plant landscape design. They apply Zen aesthetics according to their own cultural traditions. However, the essence of Zen has been spread widely.

\section{Plant landscape design development trend}

The plant landscape design based on Zen aesthetics mainly guides the modern plant landscape design from the design ideas.In the practice, we have to pay attention to the application of the modern ways. With the development of science and technology, the traditional plant landscape design cannot meet the requirements of the development of times any more. Computers and information provided many convenient ways for design. Computer-aided plant landscape design has been widely used abroad. What's more, plant landscape design software based on virtual reality technology has also been applied in some areas.

\section{Conclusion}

With the continuous development and evolution of economy and society, people's life rhythm is accelerating day by day. Under the high-pressure living conditions, people's desire for peace is increasing day by day. The living environment of reinforced concrete has caused many discomforts in people's hearts, and people are eager to return to their true selves. Integrating Zen aesthetics into 
plant landscape design is not only the need of plant design's own development, but also the call of society and the intrinsic requirement of human to explore the origin of life.

\section{References}

[1] Jin Xin. On the Realm of Zen Aesthetics and Modern Design Pursuit [J].Art and Design (Theory), 2014(08):18-20.

[2] Qin Yaping. The Beauty of Zen Space-On the Application of Zen Aesthetics in Modern Space Design [J]. Interior Design, 2015(03):17-19.

[3] Wang Qiuyang. Aesthetic Pursuit of Zen Aesthetics and Modern Interior Decoration Design [J]. Modern Decoration (Theory), 2014(09):17.

[4] Pi Chaogang. The unique nature of Zen aesthetics, human business and its contemporary enlightenment [J]. Journal of Southwest University for Nationalities (Philosophy and Social Sciences Edition), 2016 (01): 56-62.

[5] Wang Rucheng. Landscape Design [M]. Beijing: China Building Industry Press, 1999: 134-136.

[6] Zhao Shiwei, Zhang Zuoshuang. Landscape Design and Construction of Garden Plants [M]. Beijing: China Urban Economic and Social Publishing House, 2001.

[7] Wang Che. Study on Enlightenment of Zen Thoughts to Modern Garden Design [D]. Northeast Agricultural University, 2014.

[8] Wang Tingting. Confucian Moral Thought and the Layout of Royal Garden Landscape in the Qing Dynasty [D]. Northeast Forestry University, 2014.

[9] Gao Hui. Application of Jiangnan Garden Construction Method in Residential Area Landscape [D]. Hubei University of Technology, 2016. 